\title{
Some Risk factors among hypertensive Clients in an Outpatient Clinic of a Tertiary health centre, Southern Nigeria.
}

\author{
1. Allagoa Erefagha Leonardo, ${ }^{1}$ Kotingo Isuomo Victoria, ${ }^{2}$ Mukoro Duke \\ George , ${ }^{3}$ Kotingo Ebikabowei Lucky, ${ }^{1}$ Ala Cornelius Tariebi, ${ }^{1}$ Ambaiowei Segu \\ Tunumubofa, ${ }^{1}$ Asalagha Binaebi Daniel,${ }^{1}$ Enu Timipre, ${ }^{1}$ Daprim Ogaji. \\ 1.Niger-Delta University Teaching Hospital, Okolobiri, Yenagoa, Bayelsa, Nigeria. \\ 2. St George's University, School Of Medicine, West Indies. \\ 3.Federal Medical Center, Yenagoa, Bayelsa State,Nigeria
}

\begin{abstract}
:
Introduction: Hypertension has risen to become a notable public health issue, consuming a reasonable amount of various countries' health budget.Despite increasing awareness of predisposing risk factors, there is surging increase in modifiable risk factors for hypertension and so also the disease among residents in Bayelsa state. The research therefore, highlights the prevailing risk factors among known hypertensive patients in Bayelsa state and determinants.

Materials and Method: A total of 172 hypertensive patients visiting a cardiology clinic in Federal Medical Center ,Bayelsa Nigeria were recruited for the study, 93 males and 79 females. A short interview was carried out to assess risk for hypertension such a tobacco,salt consumption to already cooked food, exercise lifestyle and family history of hypertension. Total numbers recruited was determined using formulae for population sampling. Data was recorded and analyzed using SPSS.

Results: Greater than 55 percent of these clients visiting the clinics were 50 years and above, and more than 50 percent of had no educational status or of low educational status(primary level). At least a third proportion of the studied population either consume tobacco product, or add salt to already cooked food or practice exercise as lifestyle or had positive family history of hypertension. The determinants for these observations had arisen from socio-cultural background, educational status, and religious background.

Conclusion: Strategies for influencing some of the modifiable risk factors of hypertension (HTN) can only be more effective by directing public health effort to their cultural, religious and socioeconomic background.
\end{abstract}

Keywords: Hypertension, Tobacco, Exercise, Family History, salt intake

\section{Introduction.}

Hypertension in Nigeria is a widespread problem of immense social and economic importance because of its high prevalence and the severity of its complications. Hypertension has been acknowledged as the greatest and established risk factor for cardiovascular diseases. ${ }^{1}$ According to the seventh joint National committee (JNC) on prevention, detection, evaluation and treatment of high blood pressure, the prevalence estimates for hypertension may be as much as I billion individuals and approximately 7.1million deaths per year may be attributable to hypertension. ${ }^{2}$ Attention was first drawn to the racial difference in hypertension between blacks and whites in $1932 .{ }^{3}$ In a study involving 6000 blacks and 8000 whites in New Orleans, they found a higher level of elevated blood pressure among blacks. Since then, various large multi-center studies in the United States have shown that the prevalence of hypertension is much more common in blacks than in the whites ${ }^{4,5}$. The world Health organization (WHO) estimates that Hypertension associated morbidity in sub-Saharan Africa may rise to $20 \%$ by the year $2020^{6}$. It is against this background that this descriptive study was to investigate the presence of various risk factors that lead to this increased prevalence of hypertension.

Essential hypertension has no definable cause, and over $95 \%$ of cases of the disease fall under this category. ${ }^{8}$ Hypertension may be secondary to other diseases but $5 \%$ of patients have secondary hypertension which is of known origin. It is observed though that having a personal family history of hypertension increases the likelihood that an individual will develop hypertension, the disease is four times more common in black than in white people, accelerates more rapidly and is often more severe with higher mortality in black patients. ${ }^{9-12}$ intake. ${ }^{13}$

Approximately one third of the essential hypertension population is responsive to increased sodium

Cigarette smoking is a known risk factor for cardiovascular diseases, it may also be a risk factor for the development of hypertension. Sedentary lifestyle and stress have also been associated with increased risk for hypertension. The aim was of this manuscript evaluates the prevalence of risk factors of hypertension which includes smoking, exercise lifestyle, positive family history, and salt intake among hypertensive subject. 


\section{Materials And Method} Rivers State.

Bayelsa State is a state in southern Nigeria in the core of Niger Delta region, between Delta State and

The study centre was Federal medical centre(FMC) which is located in Yenagoa, the state capital, within the city centre, beside a small creek, in Yenagoa LGA of Bayelsa State and provide tertiary level health care. The study involved hypertensive patients who visited the cardiology unit of FMC.

A minimum sample size was calculated using the formula for cross sectional study and allowing $10 \%$ non-response.The statistical formula for sample size:

$$
n=\frac{Z^{2} P Q}{D^{2}}
$$

Where $n=$ minimum sample size

$Z=$ standard normal deviation set at 1.96 corresponding to $95 \%$ confidence level

$P=$ the prevalence of the attribute under study which is set at $32.3 \%$

$Q=1-\mathrm{P}=0.677$

$D=0.05$

Therefore substituting the above values into the formula;

$$
\begin{aligned}
& \mathrm{n}=\frac{1.96^{2} \times 0.323 \times 0.677}{0.05^{2}} \\
& \mathrm{n}=160.3 \approx 160 .
\end{aligned}
$$

Assuming an attrition/ non-response rate of $10 \%$

$$
\mathrm{n}=160+16=176 \text {. }
$$

The study was a descriptive cross-sectional study.

Ethical approval to conduct this study was obtained from the Ethics and Research Committee of the college of Health sciences and individual verbal informed consent was obtained from each participant before inclusion in the study. Additional assurances of confidentiality was given to all subjects.

Subjects includes all patients with Hypertension irrespective of duration of the disease.

Those that voluntarily decline consent or showed unwillingness to participate in the study after detailed explanation of the purpose of this research and the assurance of confidentiality were excluded and immediately replaced by others. The materials in this study series included ; pen, pencils, calculator, weight and height scale.

Brief interview was also taken to ascertain the presence of the other risk factors such as age, sex, practise of additional salt use already served food, tobacco and alcohol consumption and a family history. The study duration lasted for 12 weeks.

The data was analysed using the SPSS software.

\section{Results}

\begin{tabular}{|c|c|c|c|}
\hline & male & female & Total \\
\hline \multicolumn{4}{|l|}{$\overline{\text { Age(years) }}$} \\
\hline$<30$ & $14(8.1)$ & $17(9.9)$ & $31(18.0)$ \\
\hline 30-39 & $8(4.7)$ & $5(2.9)$ & $13(7.6)$ \\
\hline $40-49$ & $14(8.1)$ & $16(9.3)$ & $30(17.4)$ \\
\hline 50-59 & $23(13.4)$ & $13(7.6)$ & $36(20.9)$ \\
\hline $60+$ & $34(19.0)$ & $28(16.3)$ & $62(36.0)$ \\
\hline \multicolumn{4}{|l|}{ Educational status } \\
\hline No Formal education & $21(12.2)$ & $24(14.0)$ & $45(26.2)$ \\
\hline Primary & $39(22.7)$ & $32(18.6)$ & $71(41.3)$ \\
\hline Secondary & $16(9.3)$ & $11(6.4)$ & $27(15.7)$ \\
\hline Tertiary & $17(9.9)$ & $12(7.0)$ & $29(16.9)$ \\
\hline
\end{tabular}

The studied population revealed that greater than 55 percent of the hypertensive clients surveyed from the clinic were 50 years and above, and about half of the population are of low-educational status(non or primary). More male were affected than females. Table 1 
Some Risk factors among hypertensive Clients in An Outpatient Clinic of a Tertiary health centre,

From the Table $2 \& 3$ above, More male consume tobacco product than their female counterpart. There is a significant relationship between Age of the hypertensive patients and their consumption of Tobacco. The consumption of tobacco is more prevalent in patient within the age category of 60years and above.

The minimum period of cigarette consumption is 9year ago and the maximum period is 50years ago. The average period of cigarette consumption is approximately 20 years .

TABLE 2.0: GENDER USE OF TOBACCO

\begin{tabular}{lll|l}
\hline & male & female & Total \\
\hline \multirow{2}{*}{ Yes } & Frequency $(\%)$ & Frequency $(\%)$ & Frequency $(\%)$ \\
No & $19(11.0)$ & $13(7.6)$ & $32(18.6)$ \\
\hline \multirow{2}{*}{ Total } & $74(43.0)$ & $66(38.4)$ & $140(81.4)$ \\
\hline & $93(54.1)$ & $79(45.9)$ & $172(100.0)$ \\
\hline
\end{tabular}

Chi-square $=0.446 \quad$ P-value $=0.504$

TABLE 3: AGE Distribution for TOBACCO CONSUMPTION

\begin{tabular}{llll}
\hline Age & Yes & No & Total \\
\hline$<\mathbf{3 0}$ & 0 & $31(18.0)$ & $31(18.0)$ \\
$\mathbf{3 0 - 3 9}$ & $3(1.7)$ & $10(5.8)$ & $13(7.6)$ \\
$\mathbf{4 0 - 4 9}$ & $4(2.3)$ & $26(15.1)$ & $30(17.4)$ \\
$\mathbf{5 0 - 5 9}$ & $4(2.3)$ & $32(18.6)$ & $36(20.9)$ \\
$\mathbf{6 0 +}$ & $21(12.2)$ & $41(23.8)$ & $62(36.0)$ \\
Total & $32(18.6)$ & $140(81.4)$ & $172(100.0)$ \\
\hline
\end{tabular}

Chi-square $=\mathbf{1 8 . 6 8 5} \quad$ P-value $=0.001(<0.005)$

From the table 4, the percentage of patients who do exercises is $31.4 \%$ and those who do not do exercise is $68.6 \%$. This shows that it is a few number of patient do exercise. There is no significant difference between male or female client in their exercise activities.

The percentage of patients who has family history of hypertension is $36.6 \%$, see table 5 . Those who have no family history of hypertension is $59.9 \%$ and those who have no idea of family history of hypertension is $3.5 \%$.

TABLE4 :EXERCISE ACTIVITY AMONG DIFFERENT Genders

\begin{tabular}{lll|l}
\hline & male & Female & Total \\
\hline Yes & Frequency & Frequency & Frequency \\
No & $29(16.9)$ & $25(14.5)$ & $54(31.4)$ \\
& $64(37.2)$ & $54(31.4)$ & $118(68.6)$ \\
Total & & & $172(100.0)$ \\
\hline
\end{tabular}

Chi-square $=0.004 \quad$ P-value $=0948(>0.05)$

TABLE 5: PREVALENCE OF HYPETENSION DUE TO FAMILY HISTORY

\begin{tabular}{lll|l}
\hline \multicolumn{1}{c}{ male } & female & Total \\
\hline $\begin{array}{l}\text { Presence of } \\
\begin{array}{l}\text { Positive } \\
\text { family }\end{array}\end{array}$ & Frequency & Frequency & Frequency \\
$\begin{array}{l}\text { History } \\
\text { No family } \\
\text { history } \\
\text { No idea of } \\
\text { family } \\
\text { history }\end{array}$ & $297(193.1)$ & $46(26.7)$ & $63(36.6)$ \\
\hline Total & $4(2.3)$ & $103(59.9)$ \\
\hline
\end{tabular}

From the table 6 above, the percentage of respondents who add more salts to their food is $40.7 \%$ while those who do not add salt is $59.3 \%$. 
Some Risk factors among hypertensive Clients in An Outpatient Clinic of a Tertiary health centre,

From table 7 greater than 90 percent of the studied population were diagnosed less than or 9 years ago . This reveals that majority of the hypertensive patients were diagnosed when their age have advanced, because greater than 55 percent of persons were more than 50 years.

Table 6: SALT INTAKE practice to Served food on table

\begin{tabular}{lll|l}
\hline & male & female & Total \\
\hline \multirow{2}{*}{$\begin{array}{l}\text { Yes } \\
\text { No }\end{array}$} & Frequency (\%) & Frequency (\%) & Frequency (\%) \\
\hline \multirow{2}{*}{ Total } & $41(23.8)$ & $29(16.9)$ & $70(40.7)$ \\
& $52(30.2)$ & $50(29.1)$ & $102(59.3)$ \\
\hline
\end{tabular}

Table 7: YEARS OF DIAGNOSIS

\begin{tabular}{lll}
\hline Period of Diagnosis & Frequency & Percent \\
\hline <1 year & 16 & 9.3 \\
1-9years & 145 & 84.3 \\
10-19years & 6 & 3.5 \\
>20years & 5 & 2.9 \\
Total & 172 & 100 \\
\hline
\end{tabular}

\section{Discussion}

Hypertension becomes more prevalent after the $4^{\text {th }}$ decade of life, increasing in the frequency of occurrence in the fifth decade and reaching a peak in the 60's. This was confirmed by our study where at least 55 percent of them were above 50 years of age. Most hypertensive patients are actually diagnosed in their fifties. The middle age group is a known risk factor for development of obesity and is highly associated with it ${ }^{14}$

In comparism with a study conducted in a rural community in India, ${ }^{15}$ which identified the prevalence and risk factors for hypertension, results showed that with the exception of age, all the risk factors identified were potentially modifiable In comparism another survey in South- East Nigeria, ${ }^{16}$ which estimated the prevalence of major cardiovascular risk factors in both men and women aged 40-70 years, it showed that only the prevalence of hypertension and dysglycaemia was higher in men. Our study revealed more males than female.

This study shows that a total of $73.8 \%$ of the study population were a least formally educated at primary level, This implies that Hypertension is far more common among educated people as compared to persons without formal education, the disease is hardly reported among primitive people and is not common among the rural population.

However, in comparism to a Nigerian study, ${ }^{16}$ showed that a high prevalence of Cerebrovascular disease(CVD) risk factors existed among apparently healthy adult Nigerians, despite the fact that over $50 \%$ of are subjects illiterate. This indicates that other factors (poor socioeconomic conditions, stress) found within an illiterate population that is absent or reduced in an educated population may be responsible for the increased prevalence seen such the Nigerian study.

Other studies ${ }^{17}$, showed that the prevalence of HTN is comparable between rural populations who are predominantly illiterate as compared to urban populations who are mainly educated.

A study ${ }^{17}$, aimed to assess and compare the prevalence of hypertension and determinants of blood pressure in four sub saharan populations in rural Nigeria and Kenya, and urban Namibia and Tanzania, results revealed that the prevalence of Hypertension was comparable in both educated and illiterate populations, therefore there may not be significant difference by virtue of educational status only, but other factors tend to interplay leading to hypertension because most uneducated people aren't sedentary simply because their means of livelihood is

characterized by increased physical activity, such as farming, fishing, trading, and craftsmanship. But when they do develop hypertension, its most likely as a result of stress of life to make ends-meet. Educated people are exposed to more psychological and physical stress e.g pollution and social pressure to meet up societal demands and norms, they have reduced family social support. The educated persons are exposed to processed foods which have a high salt and fat content as well as red meat as compared to uneducated counterpart.

Most educated persons have better health seeking behaviour as compared to uneducated people, and are hence, more are like to go for a routine check-up.(most cases of HTN are diagnosed via routine check-up.)

A study ${ }^{18}$, in India, showed that males were found to be more likely to be hypertensive than females, the story may not be different with our study as well. 
The study shows that 68.6 percent of patients do not practice exercising as a lifestyle. Advancing age also deter people from exercises, which may be a factor in the study as majority of the patients were already 50 years and above. In comparism, a study conducted in Zambia showed that a sedentary lifestyle is an independent factor associated with hypertension, comparing participants who spent less than 1.5 hours sitting or reclining on a typical day with those who spent 3.5 hours or more, where $21 \%$ more likely to have hypertension. Consequently strong recommendation for health education and structural interventions to promote healthier lifestyles should be encouraged taking into account that sedentary lifestyle is a modifiable risk factors. Another study ${ }^{19}$ showed that not engaging in daily vigorous exercise, was one of five modifiable risk factors associated with incident hypertension in women, although a low risk factor.

The results of this study showed that the percentage of respondents who add salt to their already cooked food, was $40.7 \%$ which is a significant portion of the sampled population. The increased salt intake is a known modifiable risk factor of hypertension.

It is a cultural norm among the Ijaws for high taste for salt (who make up majority of the population) especially among those living in fresh water areas.

A study ${ }^{20}$, showed that increased salt intake raises blood pressure and this increase may initiate changes in arterioles and arteries that characterize hypertension. A comparism of the aforementioned study ${ }^{20}$ with ours, showed that increased salt intake is associated with Hypertension.

The results for years of diagnosis showed that an overwhelming majority of the patients have been diagnosed with HTN between 1-9 years. This reveals that on the average, most patients were exposed to some modifiable risk factors prior to their diagnosis, e.g alcohol exposure on the average is 24 years, as well as increased salt intake. This study has shown that there is an association between certain risk factors and the exposure of subjects to these risk factors as seen in the number of years before diagnosis.

From the results, the percentage of patients who smoke tobacco is $18.6 \%$. The shows that the prevalence of smoking is very low among the subjects and this may be due to; religious reasons, in Nigeria, and especially in Yenagoa most subjects are nominal Christians and smoking is a taboo in most Christian denominations, hence most people do not smoke, secondly, cultural reasons, smoking is frowned upon by the prevailing traditional systems and beliefs. Thirdly, for health reasons; the vast majority of people today are aware of the health risks associated with smoking largely due to effective public education and the mass media.The consumption of tobacco is more prevalent in patient within the age category of 60 years and above from the study. Another cultural practice which should be watched out for is the used of grounded dry tobacco dust already mixed with grounded potash stone that is sniffed by elderly in this region of Nigeria. This practice emanate from cultural background.

The percentage of patients who has family history of hypertension was $36.6 \%$.It showed that majority of the patients have no family history, while nearly a third have a positive history. However, in comparism with another study ${ }^{21}$, the prevalence of a positive family history of HTN is far higher when compared to this study. The reason for the differences, was that ,our study was done in a developing country, Nigeria, while the aforementioned study ${ }^{21}$ was in Tirane, capital of Albania. Secondly, most of respondents in a developed country would be aware of the exact diseases affecting family members as well as cause of death, essential HTN predominant among blacks, therefore can occur independent of a positive family history and some respondents in this study were not aware of any family history.

\section{Conclusion}

In this study series, risk factors prevailing among the hypertensive patients such as salt and tobacco consumption, poor exercise lifestyle, are determined by interwoven effects of culture, religion and educational, socio-economic status therefore could be modified through strategies involving the socio-cultural pattern of the people at risk for hypertension.

\section{References}

[1] Miura K. Strategies for prevention and management of hypertension throughout life. J Epidemiology, 2004; 14: 112- 117.

[2] Chobanian AV, Bakris GL, Black HR, Cushman WC, Green LA, Izzo JL Jr, Jones DW, Materson BJ, Oparil S, Wright JT Jr, Roccella EJ; Joint National Committee on Prevention, Detection, Evaluation, and Treatment of High Blood Pressure. National Heart, Lung, and Blood Institute; National High Blood Pressure Education Program Coordinating Committee.Hypertension :Epub 2003 Dec 1; 42(6):1206-52.

[3] Adam JM. Some racial differences in blood pressures and morbidity In a group of whites and colored workmen. Am J Med Sci. 1932; 184:342-349.

[4] Burt VL, Cutler JA, Higgins M et al. Trends in the prevalence, awareness, treatment and control of hypertension in the US population: Data from the Health Examination Surveys, 19960 to 1991. Hypertension. 1995; 26: 60-69

[5] Lackland DT, Keil JE :Epidemiology of hypertension in African Americans Semin Nephrol. 1996 Mar;16(2):63-70

[6] Vander Sande MA: Cardiovascular disease in Sub-Saharan Africa ; A disaster waiting to happen Neth J Med. 2003; 61: 32-36

[7] Howard BV, Lee ET, Cowan LD, Devereux RB, Galloway JM, Go OT, Howard WJ, Rhoades ER, Robbins DC, Sievers ML, Welty TK: Rising tide of Cardiovascular disease in American Indians. The Strong Heart Study. Circulation. 1999 May 11;99(18):2389-95

[8] Dickson ME, Sigmund CD (July 2006). "Genetic basis of hypertension: revisiting angiotensinogen". Hypertension 48 (1): $14-20$. 
[9] Loscazo J. Fauci A.S, Braunwald E et al: Harrison's principles of internal medicine Mc Graw- Hill medical. 18th edition (published in July 2011 by McGraw-Hill ISBN 978-0071748896) 39-43.

[10] Haffner SM, Lehto S, Rönnemaa T, Pyörälä K, Laakso M:Mortality from coronary heart disease in subjects with type 2 diabetes and in non diabetic subjects with and without prior myocardial infraction. The New England Journal of Medicine. 1998: 339 (4): 229 234.

[11] Lindhorst J. Alexander N, Blignant J. Differences in hypertension between blacks and whites, an overview. African Cardiovascular Journal - 2007; 18 (4): 241-247.

[12] Burt VL, Whelton P, Roccella EJ, Brown C, Cutler JA, Higgins M, Horan MJ, Labarthe D. prevalence of hypertension in the US adult population.Hypertension: $1995 ; 25(3): 305-313$

[13] Harvey Simon. High Blood Pressure risk factors- Health Guide. The New York Times. Sunday, December 15, 2013 .

[14] Rachel A W,Erica P G.,Elizabeth Barrett-C,Charles P Quesenberry Jr,Kristine Yaffe, Obesity in middle age and future risk of dementia: a 27 year longitudinal population based Study: BMJ 2005;330:1360.

[15] Sushil K. Bansal, Vartika Saxena, Sunil D. Kandpal, William K. Gray,Richard W. Walker, and Deepak Goel.The prevalence of hypertension and hypertension risk factors in a rural Indian community: A prospective door-to-door study. J Cardiovasc Dis Res,Vol.3(2); Apr-Jun 2012.

[16] E. C. Ejim, C. I. Okafor,A. Emehel,A. U. Mbah,U. Onyia, T. Egwuonwu,J. Akabueze,and B. J. Onwubere ${ }^{1}$. Prevalence of Cardiovascular Risk Factors in the Middle-Aged and Elderly Population of a Nigerian Rural Community. J Trop Med. 2011;

[17] Marleen E. Hendriks Ferdinand W. N. M. Wit, Marijke T. L. Roos, Lizzy M. Brewster, animola M.Akande, Ingrid H. de Beer, Sayoki G. Mfinanga, Amos M. Kahwa, Peter Gatongi,Gert Van Rooy,Wendy Janssens, Judith Lammers, Berber Kramer, Igna Bonfrer, Esegiel Gaeb, Jacques van der Gaag, Tobias F. Rinke de Wit, Joep M. A. Lange, Constance Schults; Hypertension in Sub-Saharan Africa: Cross-Sectional Surveys in Four Rural and Urban Communities,PLoS One. March 12, 2012

[18] Sher Bahadar Khan, Lubna Noor, Hafiz-ur-Rehman, Hameedullah,Mohammad Hafeezullah, Zahid Aslam Awan, Shahab ud Din, Syed Sadiq Shah: Prevalence of Hypertension Among Obese and non-obese patient with coronary Artery Disease. J Ayub Med Coll Abbottabad 2010;22(2)

[19] John P. Forman, Meir J. Stampfer,Gary C. Curhan,: Diet and Lifestyle Risk Factors Associated With Incident Hypertension in Women. JAMA. 2009;302(4):401-411.

[20] Muller MD, Ryan EJ, Bellar DM, Kim CH, Williamson ME, Glickman EL, Blankfield RP. Effect of acute salt ingestion on core temperature in healthy men. Hypertens Res. 2011 Jun;34(6):753-7.

[21] Shapo L, J Pomerleau, M McKee Epidemiology of hypertension and associated cardiovascular risk factors in a country in transition.J Epidemiol Community Health 2003;57:734-739 